\title{
Open Culture Ethanol-Based Chain Elongation to Form Medium Chain Branched Carboxylates and Alcohols
}

\author{
Kasper D. de Leeuw, Theresa Ahrens, Cees J. N. Buisman and David P. B. T. B. Strik* \\ Environmental Technology, Wageningen University \& Research, Wageningen, Netherlands
}

Chain elongation fermentation allows for the synthesis of biobased chemicals from complex organic residue streams. To expand the product spectrum of chain elongation technology and its application range we investigated 1) how to increase selectivity towards branched chain elongation and 2) whether alternative branched carboxylates such as branched valerates can be used as electron acceptors. Elongation of isobutyrate elongation towards 4-methyl-pentanoate was achieved with a selectivity of $27 \%$ (of total products, based on carbon atoms) in a continuous system that operated under $\mathrm{CO}_{2}$ and acetate limited conditions. Increasing the $\mathrm{CO}_{2}$ load led to more in situ acetate formation that increased overall chain elongation rate but decreased the selectivity of branched chain elongation. A part of this acetate formation was related to

Edited by: Madalena Santos Alves, University of Minho, Portugal

Reviewed by: Bastian Molitor, University of Tübingen, Germany Sandrine Alfenore, Institut Biotechnologique de Toulouse (INSA), France

${ }^{*}$ Correspondence:

David P. B. T. B. Strik david.strik@wur.nl

Specialty section: This article was submitted to

Bioprocess Engineering,

a section of the journal Frontiers in Bioengineering and Biotechnology

Received: 19 April 2021 Accepted: 30 July 2021 Published: 17 August 2021

Citation: de Leeuw KD, Ahrens T, Buisman CJ N and Strik DPBTB (2021) Open Culture

Ethanol-Based Chain Elongation to Form Medium Chain Branched

Carboxylates and Alcohols.

Front. Bioeng. Biotechnol. 9:697439.

doi: 10.3389/fbioe.2021.697439 direct ethanol oxidation that seemed to be thermodynamically coupled to hydrogenotrophic carboxylate reduction to corresponding alcohols. Several alcohols including isobutanol and $n$-hexanol were formed. The microbiome from the continuous reactor was also able to form small amounts of 5-methyl-hexanoate likely from 3-methylbutanoate and ethanol as substrate in batch experiments. The highest achieved concentration of isoheptanoate was $6.4 \pm 0.9 \mathrm{mM}$ Carbon, or $118 \pm 17 \mathrm{mg} / \mathrm{L}$, which contributed for $7 \%$ to the total amount of products (based on carbon atoms). The formation of isoheptanoate was dependent on the isoform of branched valerate. With 3-methyl-butanoate as substrate 5-methylhexanoate was formed, whereas a racemic mixture of L/D 2-methyl-butanoate did not lead to an elongated product. When isobutyrate and isovalerate were added simultaneously as substrates there was a large preference for elongation of isobutyrate over isovalerate. Overall, this work showed that chain elongation microbiomes can be further adapted with supplement of branched-electron acceptors towards the formation of iso-caproate and iso-heptanoate as well as that longer chain alcohol formation can be stimulated.

Keywords: microbial chain elongation, open culture fermentation, branched carboxylates, medium chain fatty acids, medium chain fatty alcohols, bioprocess engineering

\section{INTRODUCTION}

Chain elongation fermentation is an emerging bioprocess by which medium chain carboxylates (MCCs) can be produced. Currently, MCCs are mainly produced from either non-renewable fossil resources or palm and kernel oil-crops (Ahmad et al., 2019; Tan and Lim, 2019). Chain elongation fermentations provide a sustainable alternative by utilizing organic residue streams as substrate 
(Agler et al., 2011; Agler et al., 2012). In general, these fermentations require electron acceptors in the form of short chain carboxylates (e.g., acetate, propionate, butyrate, valerate), that can be obtained after hydrolysis and acidification of organic residues. An electron donor such as ethanol is then required to elongate the short chain carboxylates to MCCs (De Groof et al., 2019). Microbial chain elongation provides an economically attractive alternative to biogas formation (Kleerebezem et al., 2015). MCCs in general can be used in the production of e.g., solvents, feed additives (Liu et al., 2018), lubricants, surfactants, emulsifiers, pharmaceuticals (Angenent et al., 2016) and as precursors for plastics and fuels (Levy et al., 1984; Zhang et al., 2004). The amount of research on the formation of straight MCCs such as n-caproate $\left(n-C_{6}\right)$ and n-caprylate $\left(\mathrm{n}-\mathrm{C}_{8}\right.$ ) via microbial chain elongation is quickly expanding (Steinbusch et al., 2011; Zhu et al., 2015; Angenent et al., 2016; Zhu et al., 2017; Chwialkowska et al., 2019; Han et al., 2019; Leng et al., 2019). Chain elongation fermentation technology could become an impactful recycling method that can aid in the development of a circular economy (De Groof et al., 2019).

This research focuses on expanding the product spectrum of microbial chain elongation using synthetic media, with the aim to broaden the application range of the technology. Recently it was also shown that branched MCC isocaproate $\left(\mathrm{i}-\mathrm{C}_{6}\right.$ ) can be formed in considerable amounts when isobutyrate $\left(\mathrm{i}-\mathrm{C}_{4}\right)$ is used as electron acceptor in an open-culture ethanol based chain elongation fermentation (de Leeuw et al., 2019). This research suggests that formation of other branched MCCs such as isoheptanoate $\left(\mathrm{i}-\mathrm{C}_{7}\right)$ should be possible. The necessary isovalerate $\left(\mathrm{i}-\mathrm{C}_{5}\right)$ substrate could be formed prior to chain elongation via protein degradation steps during acidification (Allison, 1978; Yang et al., 2016). Branched MCCs exhibit different physical properties compared to straight MCCs, which can make them more suitable for various applications. Branched MCCs have a higher viscosity, a reduced crystallization temperature (Lee et al., 1995) and have an oxidative stability (Zhang et al., 2004; Atsumi et al., 2008) that can improve fuel combustion (Ghosh et al., 2006).

In addition to MCCs, higher alcohols can be coproduced within a chain elongation microbiome (Diender et al., 2016; Richter et al., 2016; de Leeuw et al., 2019). In some cases, acetate and $\mathrm{CO}_{2}$ limitation triggered alcohol formation during ethanol-based chain elongation (de Leeuw et al., 2019). During syngas-facilitated chain elongation a low $\mathrm{pH}(\sim 4.8)$ triggered alcohol formation (Ganigué et al., 2016). A better understanding on their production mechanism could facilitate the development of higher alcohol formation from complex organic residues, rather than from more expensive glucose-based fermentations (Chen et al., 2013; Xin et al., 2014).

In open culture fermentations the microbiomes should be enriched in such a way that the metabolic fluxes responsible for electron donor and acceptor consumption are directed towards the formation of the desired products. A challenge with ethanolbased chain elongation fermentations is minimizing the activity of direct ethanol oxidation, that can occur independent of chain elongation and is directly competing for the electron donor ethanol. For ethanol-based chain elongation the following stoichiometry is observed (Angenent et al., 2016):

$$
\begin{aligned}
& 5 \mathrm{C}_{\mathrm{X}} \mathrm{H}_{2 \mathrm{X}-1} \mathrm{O}_{2}^{-}+6 \mathrm{C}_{2} \mathrm{H}_{6} \mathrm{O} \rightarrow 5 \mathrm{C}_{\mathrm{X}+2} \mathrm{H}_{2 \mathrm{X}+3} \mathrm{O}_{2}^{-1}+\mathrm{C}_{2} \mathrm{C}_{3} \mathrm{O}_{2}^{-}+4 \mathrm{H}_{2} \mathrm{O} \\
& +\mathrm{H}^{+}+2 \mathrm{H}_{2}
\end{aligned}
$$

(equation 1)

With (excessive) direct ethanol oxidation this following conversion is regarded (Roghair et al., 2018a):

$$
\mathrm{C}_{2} \mathrm{H}_{6} \mathrm{O}+\mathrm{H}_{2} \mathrm{O} \rightarrow \mathrm{C}_{2} \mathrm{H}_{3} \mathrm{O}_{2}^{-}+\mathrm{H}^{+}+2 \mathrm{H}_{2} \quad \text { (equation 2) }
$$

Direct ethanol oxidation is thermodynamically feasible at a hydrogen partial pressure below approximately $1 \mathrm{kPa}$ and can be stimulated when syntrophic partners in biofilms utilize the produced hydrogen (Seitz et al., 1990; Nozhevnikova et al., 2020). The usage of ethanol has a big impact on the sustainability and costs of the ethanol-based chain elongation process, and as such excess consumption should be avoided at all cost (Chen et al., 2017). Additionally, the insitu acetate formation reduces the selectivity of branched and odd-chain carboxylate elongation (Grootscholten et al., 2013a; de Leeuw et al., 2019). Earlier research has shown that reducing the $\mathrm{CO}_{2}$ dosage could reduce excessive ethanol oxidation and increase carboxylate elongation selectivity (Roghair et al., 2018a).

The objective of this study was to investigate branched electron acceptors for the formation of $\mathrm{i}-\mathrm{C}_{6}$ and $\mathrm{i}-\mathrm{C}_{7}$ by ethanol-based chain elongation reactor microbiomes. A continuous anaerobic filter bioreactor that was fed with ethanol and $\mathrm{i}-\mathrm{C}_{4}$ was operated under two different $\mathrm{CO}_{2}$ loads and used enrich a microbiome for chain elongation activity. The results indicate that branched chain elongation selectivity was indeed higher at low $\mathrm{CO}_{2}$ loads. This effect, however, could be transient due to microbiome adaptation that led to increased functionality of alcohol formation, which seemed to be coupled to direct ethanol oxidation.

The same microbiome was used in batch experiments to evaluate the feasibility of using branched five-carbon carboxylates ( $\mathrm{i}-\mathrm{C}_{5}$ and L/D 2-methyl butanoate) as substrate and electron acceptor within an ethanol-based chain elongation microbiome. Hypothetically L/D 4-methylhexanoate is the elongation product of $\mathrm{L} / \mathrm{D} 2$-methylbutyrate, whereas $\mathrm{i}-\mathrm{C}_{7}$ is the elongation product of $\mathrm{i}-\mathrm{C}_{5}$, assuming the elongation occurs in a similar fashion as during earlier observed $\mathrm{i}-\mathrm{C}_{4}$ elongation to i- $\mathrm{C}_{6}$ and other chain elongation mechanisms (Kim et al., 2019). We show the likely formation of $\mathrm{i}-\mathrm{C}_{7}$ via microbial i- $\mathrm{C}_{5}$ (3methylbutanoate) elongation using ethanol as electron donor. After this observation, another batch series was performed to evaluate the effect of higher initial hydrogen partial pressure and acetate concentrations that are known to influence the chain elongation activity (Steinbusch et al., 2011; Spirito et al., 2014; Angenent et al., 2016; de Leeuw et al., 2019). In addition, substrate specificity of $\mathrm{i}-\mathrm{C}_{5}$ was compared to that of $\mathrm{i}-\mathrm{C}_{4}$ as an alternative substrate and electron acceptor. The results highlight that branched chain elongation hypothetically occurs as cometabolism during straight chain elongation, meaning that a 
TABLE 1 | Overview over the different phases in the reactor. The influent carbon sources, the steady state duration for each phase, the HRT, pH and CO2 supply are listed.

\begin{tabular}{|c|c|c|c|c|}
\hline Phase & I & II & III & IV \\
\hline Condition & Start-up & Add carrier material & $\mathrm{CO}_{2}$ increase & $\mathrm{CO}_{2}$ decrease \\
\hline Phase period (days) & $1-45$ & $45-78$ & 78-94 & $94-129$ \\
\hline HRT (h) & $44 \pm 7$ & $46 \pm 8$ & $44 \pm 2$ & $47 \pm 6$ \\
\hline Isobutyrate (mM C) & 650 & 650 & 650 & 650 \\
\hline Ethanol (mM C) & 540 & 540 & 540 & 540 \\
\hline $\mathrm{PH}$ & $6.65 \pm 0.07$ & $6.6 \pm 0.03$ & $6.6 \pm 0.02$ & 6.62 \\
\hline $\mathrm{CO}_{2}$ supply ( $\left.\mathrm{NmL} / \mathrm{min}\right)$ & 0.18 & 0.18 & 0.36 & 0.18 \\
\hline
\end{tabular}

minimum amount of acetate is required for branched chain elongation to occur at all.

\section{MATERIALS AND METHODS}

\section{Continuous Reactor Setup}

A continuous anaerobic filter bioreactor was set up to investigate the effect of $\mathrm{CO}_{2}$ supply on isobutyrate chain elongation. The reactor system $(35 \mathrm{~cm}$ height, an internal column diameter of $6.5 \mathrm{~cm}$, a $1 \mathrm{~L}$ working liquid volume, and a headspace of $0.15 \mathrm{~L}$ ) was exactly the same as in previous research on isocaproate formation via ethanol based chain elongation (de Leeuw et al., 2019), except for the addition of a carrier material. This was done to retain microbial biomass and to increase the rate of chain elongation activity (Grootscholten et al., 2013b). After startup (phase I), the reactor was filled with sponge carrier material ( $0.15 \mathrm{~L}$ liquid exclusion volume of 15 by $15 \mathrm{~mm}$ polyurethane cubes; Recticel, Belgium) to support additional growth of biomass (phase II). To maintain anaerobic conditions during this procedure the reactor was flushed with $\mathrm{N}_{2}$ gas. The addition of cubes changed the active liquid volume of the reactor from 1 to $0.85 \mathrm{~L}$. The influent rate was adjusted accordingly (from $22.2 \mathrm{mlh}^{-1}-18.9 \mathrm{mlh}^{-1}$ ) to maintain a hydraulic retention time (HRT) of around $45 \mathrm{~h}$. The $\mathrm{CO}_{2}$ supply was doubled in phase III and halved again in phase IV. An overview of the influent carbon sources, the steady state duration for each phase, the HRT, pH and the CO2 supply for the different phases are listed in Table 1.

\section{Medium}

The reactor was fed with $650 \mathrm{mmol}$ Carbon $\mathrm{L}^{-1}$ (mMC) isobutyrate, $540 \mathrm{mMC}$ ethanol and $1 \mathrm{gL}^{-1}$ yeast extract [ $34 \mathrm{mMC}$ (Duboc et al., 1995)] as carbon sources (acetate was omitted from the influent). The reactor and batch experiments were all done using the same macro- and micronutrient composition $\left(\mathrm{g} \mathrm{L}^{-1}\right)$ : $\mathrm{NH}_{4} \mathrm{H}_{2} \mathrm{PO}_{4} 3.60$; $\mathrm{MgCl}_{2} \cdot 6 \mathrm{H}_{2} \mathrm{O} 0.33 ; \mathrm{MgSO}_{4} \cdot 7 \mathrm{H}_{2} \mathrm{O} 0.20 ; \mathrm{CaCl}_{2} \cdot 2 \mathrm{H}_{2} \mathrm{O} 0.20 ; \mathrm{KCl} 0.15$. In addition, the micronutrients (Pfennig trace metals and B-vitamins) of the designed basal medium described in Phillips $j$ et al. (1993) was used.

\section{Batch Experimental Setup}

The batch experiments were performed in $250 \mathrm{ml}$ serum bottles (150 $\mathrm{ml}$ liquid medium). The remaining $100 \mathrm{ml}$ gas headspace was replaced at the start of each batch up to a pressure of $150 \mathrm{kPa}$ (see gas composition per batch in Tables 1-3). The batch bottles were kept in a shaker at $35^{\circ} \mathrm{C}$ and $150 \mathrm{rpm}$ throughout the whole experiment. The exact step-by-step protocol for the batches is given in the Supplementary Information, including the recipes for the medium preparation stock solutions (Supplementary Tables S1, S4). All batches were carried out in duplicates.

\section{Investigating i-C5 Elongation Proof of Concept-First Batch Series}

The first experimental series consisted of eight batches (1.A to 1.H) that aimed to investigate if an enriched microbiome that produced i- $\mathrm{C}_{6}$ could also elongate branched valerates to branched heptanoates. Ethanol (160 or $320 \mathrm{mMC}$ ) and acetate (6.5 or $13 \mathrm{mMC}$ ) were always added as substrate, whereas the types of branched valerates were varied throughout the series. In batch 1.A and 1.B a racemic mixture of L/D 2-methylbutanoate was added. $\mathrm{I}^{-C_{5}}$ (i.e., 3methylbutanoate) was added in batch 1.C and 1.D. In batch 1.E and 1.F a 50:50 mixture of the L/D 2-methylbutanoate racemate and i- $C_{5}$ was added to investigate their combined effect on chain elongation. All these batches were performed at two different substrate concentrations (Table 2), because it was unknown to what degree the (potentially toxic) branched valerates could affect the chain elongation process. BES (2-bromoethanesulfanoate) was added at $10 \mathrm{~g} / \mathrm{L}$ to inhibit methanogenesis (Vogels et al., 1982), except in the control batch 1.G. Additionally a control batch (1.H) was performed without yeast extract to be able to exclude the possible formation of $\mathrm{i}-\mathrm{C}_{7}$ from yeast extract.

\section{Investigating the Substrate Specificity and Limiting Factors for Chain Elongation Activity-Second and Third Batch Series}

In the first batch series ethanol was not completely converted and it remained unclear if this was caused by the drop in $\mathrm{pH}$, a limiting acetate concentration, the increased hydrogen partial pressure or something else [such as product inhibition on the microbiome (Roghair et al., 2018b)]. Therefore, a second and third series were performed to further investigate the effect of increased hydrogen partial pressure in combination with different starting acetate concentrations. In contrast to the first series that contained no hydrogen at the start of the experiment, the second series was performed with hydrogen already present in the headspace at the start of the batch (20\% for all batches, except 2.C which contained $80 \% \mathrm{H}_{2}$ at the start). This was done to minimize acetate formation via potential excessive ethanol oxidation which is thermodynamically inhibited at higher $\mathrm{H}_{2}$ pressures (Roghair et al., 2018a) and to investigate the effect of an elevated $\mathrm{H}_{2}$ 
TABLE 2 | Overview of the different starting parameters $(t=0)$ for the first batch series, as well as final values ( $t=$ end) for product selectivites (\% of total formed compounds based on carbon atoms) of $\mathrm{i}-\mathrm{C}_{7}, \mathrm{n}-\mathrm{C}_{6}$ and hexanol, the percentages of unconverted ethanol at the end of the batch, $\mathrm{pH}$ and partial pressures of $\mathrm{CO}_{2}$ and $\mathrm{H}_{2}$.

\begin{tabular}{|c|c|c|c|c|c|c|c|c|}
\hline & 1.A & 1.B & $1 . \mathrm{C}$ & 1.D & 1.E & $1 . F$ & $1 . G$ & $1 . H$ \\
\hline $\mathrm{EtOH}(\mathrm{mM} \mathrm{C})$ & 320 & 160 & 320 & 160 & 320 & 160 & 160 & 160 \\
\hline Acetate (mM C) & 13 & 6.5 & 13 & 6.5 & 13 & 6.5 & 6.5 & 6.5 \\
\hline L/D 2-methylbutanoate (mM C) & 325 & 162.5 & - & - & 162.5 & 81.3 & - & - \\
\hline (3-) $\mathrm{i}-\mathrm{C}_{5}(\mathrm{mM} \mathrm{C})$ & - & - & 325 & 162.5 & 162.5 & 81.3 & 162.5 & 162.5 \\
\hline $\operatorname{BES}(g / L)$ & 10 & 10 & 10 & 10 & 10 & 10 & - & 10 \\
\hline Yeast (g/L) & 0.5 & 0.5 & 0.5 & 0.5 & 0.5 & 0.5 & 0.5 & - \\
\hline $\mathrm{pH}$ & 6.5 & 6.5 & 6.5 & 6.5 & 6.5 & 6.5 & 6.5 & 6.5 \\
\hline $\mathrm{N}_{2}(\%)$ & 90 & 90 & 90 & 90 & 90 & 90 & 90 & 90 \\
\hline $\mathrm{CO}_{2}(\%)$ & 10 & 10 & 10 & 10 & 10 & 10 & 10 & 10 \\
\hline $\mathrm{H}_{2}(\%)$ & 0 & 0 & 0 & 0 & 0 & 0 & 0 & 0 \\
\hline $\mathrm{i}-\mathrm{C}_{7}$ selectivity (\%) & 0 & 0 & 4.1 & 2.9 & 0.6 & 0.9 & 5.4 & 2.5 \\
\hline $\mathrm{n}-\mathrm{C}_{6}$ selectivity $(\%)$ & 75.9 & 82.0 & 87.1 & 75.0 & 79.3 & 82.8 & 85.7 & 89.8 \\
\hline Hexanol selectivity (\%) & 1.5 & 3.5 & 4.3 & 6.0 & 2.8 & 3.8 & 2.9 & 4.5 \\
\hline Unconverted ethanol (\%) & 73.4 & 56.4 & 74.5 & 54.8 & 77.6 & 53.2 & 65.7 & 47.6 \\
\hline Final $\mathrm{pH}$ & 5.9 & 5.9 & 6.1 & 5.8 & 6.0 & 5.9 & 5.7 & 6.1 \\
\hline Final $\mathrm{CO}_{2}$ partial pressure $(\mathrm{kPa})$ & 4.3 & 5.3 & 7.1 & 4.1 & 7.1 & 3.1 & 0.1 & 5.1 \\
\hline Final $\mathrm{H}_{2}$ partial pressure $(\mathrm{kPa})$ & 20.3 & 17.7 & 29.7 & 11.8 & 27.4 & 17.1 & 2.9 & 21.3 \\
\hline
\end{tabular}

TABLE 3 | Overview of the different starting parameters $(t=0)$ for the second batch series, as well as final values $(t=e n d)$ for product selectivites $(\%$ of total formed compounds based on carbon atoms) of $\mathrm{i}-\mathrm{C}_{7}, \mathrm{n}-\mathrm{C}_{6}$ and hexanol, the percentages of unconverted ethanol at the end of the batch, $\mathrm{pH}$ and partial pressures of $\mathrm{CO}_{2}$ and $\mathrm{H}_{2}$.

\begin{tabular}{|c|c|c|c|c|}
\hline & 2.A (low acetate) & 2.B (high acetate) & 2.C (high hydrogen) & 2.D (including $\mathrm{i}-\mathrm{C}_{4}$ ) \\
\hline Inoculum & Batch 1.D & Batch 1.D & Batch 1.D & Batch 1.D \\
\hline EtOH (mM C) & 160 & 160 & 160 & 160 \\
\hline (3-) $\mathrm{i}-\mathrm{C}_{5}(\mathrm{mM} \mathrm{C})$ & 162.5 & 162.5 & 162.5 & 162.5 \\
\hline $\mathrm{i}-\mathrm{C}_{4}(\mathrm{mM} \mathrm{C})$ & - & - & - & 64.5 \\
\hline Acetate (mM C) & 6.5 & 65 & 6.5 & 6.5 \\
\hline BES $(g / L)$ & 10 & 10 & 10 & 10 \\
\hline Yeast (g/L) & 0.5 & 0.5 & 0.5 & 0.5 \\
\hline $\mathrm{pH}$ & 7 & 7 & 7 & 7 \\
\hline $\mathrm{N}_{2}(\%)$ & 70 & 70 & 10 & 70 \\
\hline $\mathrm{CO}_{2} \%$ & 10 & 10 & 10 & 10 \\
\hline $\mathrm{H}_{2}(\%)$ & 20 & 20 & 80 & 20 \\
\hline $\mathrm{i}-\mathrm{C}_{7}$ selectivity (\%) & 7.3 & 1.4 & 7.1 & 4.2 \\
\hline $\mathrm{n}-\mathrm{C}_{6}$ selectivity $(\%)$ & 79.4 & 81.9 & 80.8 & 56.9 \\
\hline Hexanol selectivity (\%) & 4.8 & 2.1 & 3.9 & 1.4 \\
\hline Unconverted ethanol (\%) & 58.0 & 4.8 & 72.5 & 61.4 \\
\hline Final $\mathrm{pH}$ & 6.5 & 6.3 & 6.6 & 6.6 \\
\hline Final $\mathrm{CO}_{2}$ partial pressure $(\mathrm{kPa})$ & 1.8 & 2.1 & 2.2 & 3.8 \\
\hline Final $\mathrm{H}_{2}$ partial pressure (kPa) & 32.1 & 60.0 & 110.7 & 41.9 \\
\hline
\end{tabular}

pressure on the chain elongation itself (Li et al., 2008; Angenent et al., 2016). These batches were all started at pH 7 instead of 6.5 to allow for more proton formation due to ethanol oxidation before $\mathrm{pH}$ drops down to limiting levels. When the $\mathrm{pH}$ drops below 6.3 it could cause limitations in bicarbonate availability (Tomlinson, 1954; Jungermann et al., 1968). When the pH drops even further and approaches $\mathrm{pK}$ values of the carboxylates ( 4.9), undissociated fatty acids concentrations rise which causes additional toxicity effects (Infantes et al., 2012). One batch (2.B) was started with an initial acetate concentration ten times higher than the control (2.A). Additionally, to investigate the necessity of acetate during chain elongation, batch $3 . \mathrm{B}$ was started with zero added acetate (3.A as control, in the third batch series).
To batch 2.D i- $\mathrm{C}_{4}$ was added in addition to $\mathrm{i}-\mathrm{C}_{5}$ to get insight into substrate preferences for branched chain elongation. In the third batch series n-valerate was added (batch 1.D) to compare its utilization as electron acceptor with $\mathrm{i}-\mathrm{C}_{5}$ and exclude possible $\mathrm{i}-\mathrm{C}_{7}$ formation via $\mathrm{n}-\mathrm{C}_{5}$. Tables 3,4 show overviews of the second and third batch series, respectively. The medium was the same as the medium from the first series, except for the indicated changes in the tables.

\section{Inoculum}

The continuous reactor as well as the first batch series was inoculated with a mixture of two anaerobic cultures. One volume part was taken from the continuous reactor that 
TABLE 4 | Overview of the different starting parameters $(t=0)$ for the third batch series, as well as final values $(t=$ end) for product selectivites ( $\%$ of total formed compounds based on carbon atoms) of $\mathrm{i}-\mathrm{C}_{7}, \mathrm{n}-\mathrm{C}_{6}$ and hexanol, the percentages of unconverted ethanol at the end of the batch, $\mathrm{pH}$ and partial pressures of $\mathrm{CO}_{2}$ and $\mathrm{H}_{2}$.

\begin{tabular}{|c|c|c|c|c|}
\hline & 3.A (low acetate) & 3.B (no acetate) & $\begin{array}{c}\text { 3.C } \\
\text { (no extra carboxylate) }\end{array}$ & 3.D $\left(n-C_{5}\right)$ \\
\hline Inoculum & regrown 2.D & regrown 2.D & regrown 2.D & regrown 2.D \\
\hline $\mathrm{EtOH}(\mathrm{mM} \mathrm{C})$ & 320 & 320 & 320 & 320 \\
\hline (3-) $\mathrm{i}-\mathrm{C}_{5}(\mathrm{mM} \mathrm{C})$ & 162.5 & 162.5 & - & - \\
\hline $\mathrm{n}-\mathrm{C}_{5}(\mathrm{mM} \mathrm{C})$ & - & - & - & 162.5 \\
\hline Acetate (mM C) & 13 & 0 & 13 & 13 \\
\hline BES (g/L) & 10 & 10 & 10 & 10 \\
\hline Yeast (g/L) & 0.5 & 0.5 & 0.5 & 0.5 \\
\hline $\mathrm{pH}$ & 7 & 7 & 7 & 7 \\
\hline $\mathrm{N}_{2}(\%)$ & 60 & 60 & 60 & 60 \\
\hline $\mathrm{CO}_{2} \%$ & 20 & 20 & 20 & 20 \\
\hline $\mathrm{H}_{2}(\%)$ & 20 & 20 & 20 & 20 \\
\hline $\mathrm{i}-\mathrm{C}_{7}$ selectivity (\%) & 3.2 & 3.8 & 0 & 0 \\
\hline $\mathrm{n}-\mathrm{C}_{6}$ selectivity (\%) & 83.2 & 82.3 & 68.2 & 62.5 \\
\hline Hexanol selectivity (\%) & 1.8 & 1.8 & 1.6 & 2.4 \\
\hline Unconverted ethanol (\%) & 53.1 & 58.0 & 22.1 & 41.6 \\
\hline Final $\mathrm{pH}$ & 6.0 & 6.1 & 5.8 & 6.0 \\
\hline Final $\mathrm{CO}_{2}$ partial pressure $(\mathrm{kPa})$ & 0.3 & 0.4 & 0.3 & 1.1 \\
\hline Final $\mathrm{H}_{2}$ partial pressure $(\mathrm{kPa})$ & 15.0 & 8.9 & 10.2 & 18.9 \\
\hline
\end{tabular}

elongated i- $\mathrm{C}_{4}$ to $\mathrm{i}-\mathrm{C}_{6}$ (de Leeuw et al., 2019) and contained a $C$. kluyveri dominant culture; second equal volume part came from an undefined mixed bovine rumen sample. The bovine rumen liquid from three cows was provided by the Animal Science Department of Wageningen University and Research. Biomass concentration was not measured within the inocula. The inocula were centrifuged at $4,500 \mathrm{rpm}$ for $10 \mathrm{~min}$ after which the cell pellets were resuspended in carbon source free medium prior to inoculation as described within the step-by-step protocol in the Supplementary Information section.

The inoculum for the second batch series was taken from batch 1.D of the first series. Its contents were centrifuged in $50 \mathrm{ml}$ tubes at $4,500 \mathrm{rpm}$ and the pellets were subsequently combined and re-suspended with $50 \mathrm{ml}$ carbon source free medium. These re-suspended cells were then used as inoculum for the second batch series as described within the step-by-step protocol. Similarly, the third batch series was inoculated with biomass that originated from batch 2.D. However, before inoculating, batch 2.D was stored for one and a half year at room temperature. Sporulation of bacteria was observed under the microscope, prior to activation. Before starting the third batch series an activation batch was performed using the same conditions as in batch 2.D. The third batch series was then inoculated with this freshly activated biomass.

\section{Sampling and Measurement}

Samples of the gas phase were taken once per week and analyzed using an established protocol for gas chromatography to determine the fractions of $\mathrm{O}_{2}, \mathrm{~N}_{2}, \mathrm{CH}_{4}, \mathrm{H}_{2}$, and $\mathrm{CO}_{2}$ (Steinbusch et al., 2011; Chen et al., 2016). Before sampling the pressure was measured using a pressure meter (GMH 3151). At the same time liquid samples $(3.5 \mathrm{ml})$ were taken, centrifuged at 10,000 rpm and stored in a freezer at $-20^{\circ} \mathrm{C}$. Every 2 weeks these samples were analyzed according an earlier described gas chromatography method (Agilent 7890B,
United States, HP-FFAP column, FID detector) (Jourdin et al., 2018) to determine the concentrations of primary alcohols and volatile carboxylic acids (ethanol, propanol, butanol, iso-butanol, pentanol, branched pentanols, n-hexanol, iso-hexanol and acetate, n-butyrate, iso-butyrate, n-valerate, branched valerates, n-caproate, iso-caproate, $\mathrm{n}$-heptanoate, iso-heptanoate and n-caprylate). The branched valerates $\mathrm{i}-\mathrm{C}_{5}$ and $\mathrm{L} / \mathrm{D}$ 2-methylbutyrate as well as the branched pentanols isopentanol and L/D 2-methylbutanol could not be distinguished with the available equipment because the isomers exhibited the same retention time. Therefore, the batches were designed to investigate their effect on chain elongation separately to analyze which isomers of branched valerates were used for the formation of which branched heptanoate. The expected forms of branched heptanoates, L/D 4-methylhexanoate and $\mathrm{i}-\mathrm{C}_{7}$, could be distinguished as is shown in Supplementary Figure S1 in the Supplementary Information. For the continuous experiment, the data is presented using the averaged values during each phase and a confidence interval $( \pm)$ using an a of 0.1. For depiction of the batches, the duplicate results are averaged, and the error bars indicate the differences between each measurement within the duplicate. For the carbon and electron balance calculation (see SI page 5 for equations) yeast extract was assumed to be completely consumed.

\section{RESULTS}

\section{Continuous Reactor Increasing and Subsequently Decreasing $\mathrm{CO}_{2}$ Loading Rate}

During the first 3 weeks after starting the isobutyrate $\left(\mathrm{i}-\mathrm{C}_{4}\right)$ and ethanol $(\mathrm{EtOH})$ fed continuous bioreactor, acetate $\left(\mathrm{C}_{2}\right)$ accumulated in the broth, followed by n-butyrate $\left(n-C_{4}\right)$, n-butanol $\left(\mathrm{n}-\mathrm{C}_{4} \mathrm{OH}\right)$ and isobutanol $\left(\mathrm{i}-\mathrm{C}_{4} \mathrm{OH}\right)$ (Figure 1). Around day 30 the broth concentration of these compounds, except for $\mathrm{i}-\mathrm{C}_{4} \mathrm{OH}$, decreased while n-caproate $\left(\mathrm{n}-\mathrm{C}_{6}\right)$ and 

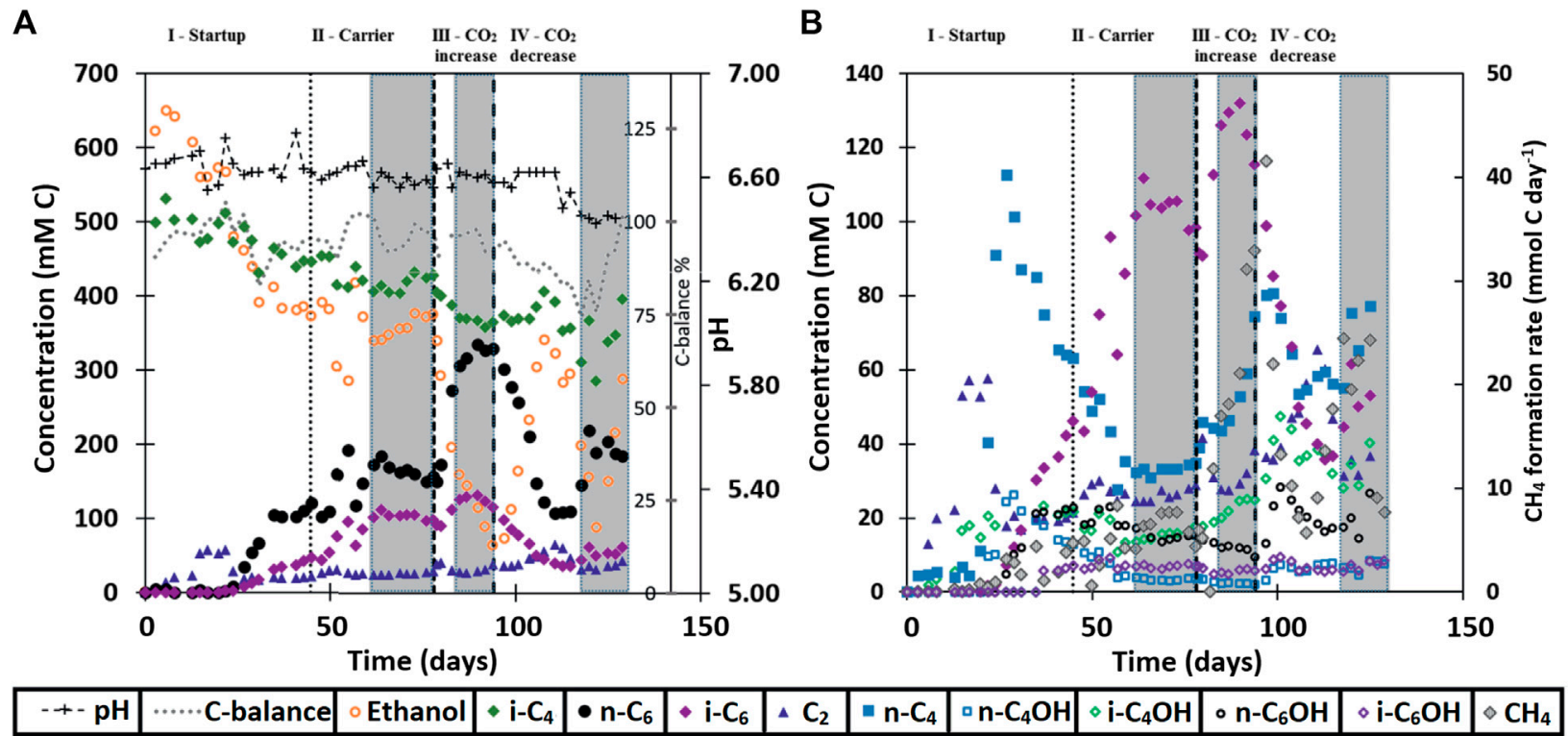

FIGURE 1 | Broth concentrations of metabolites within the continuous reactor system. Additionally, the carbon balance and pH are shown in (A) and methane formation is rate shown in (B). The grey boxes at the end of each phase show the range where the averages were taken for the values in Table $\mathbf{5}$

TABLE 5 | Overview of averaged operating parameters and conversion rates including confidence intervals. Averages from phase IV are taken when caproate formation had stabilized (day 106-113).

\section{Phase II}

Add carrier material

day $45-78$

day $62-78$
Phase III

$\mathrm{CO}_{2}$ increase

day 78-94

day 85-94
Phase IV

$\mathrm{CO}_{2}$ decrease

day $94-129$

day $117-129$

Averages taken from

$21 \quad \pm 7$

Calculated Excessive ethanol Oxidation (\%)

HRT (hours)

$\mathrm{pH}$

$\mathrm{CO}_{2}$ loading $\left(\mathrm{NmL} \mathrm{min}^{-1}\right)$

$46 \quad \pm 8$

C-balance (\%)

e-balance (\%)

$6.60 \quad \pm 0.03$

0.18

96

$\pm 3$

$\pm 3$

25
44
6.60
0.36

\pm 1
\pm 8
\pm 0
\pm 3
\pm 5
\pm 0
\pm 13
\pm 0
\pm 1
\pm 1
\pm 0
\pm 1
\pm 0

95
97

Volumetric conversion rates ( $\mathrm{mmol} \mathrm{C} \mathrm{L}{ }^{-1}$ day $^{-1}$ )

$\begin{array}{cc}13 & \pm 1 \\ -49 & \pm 8 \\ 17 & \pm 0 \\ 50 & \pm 3 \\ 82 & \pm 5 \\ 2 & \pm 0 \\ -134 & \pm 13 \\ 2 & \pm 0 \\ 8 & \pm 1 \\ 8 & \pm 1 \\ 1 & \pm 0 \\ 6 & \pm 1 \\ -11 & \pm 0\end{array}$

$\mathrm{C}_{2}$

$\mathrm{i}-\mathrm{C}_{4}$

$\mathrm{n}-\mathrm{C}_{4}$

$\mathrm{i}-\mathrm{C}_{6}$

$\mathrm{n}-\mathrm{C}_{6}$

$\mathrm{n}-\mathrm{C}_{8}$

$\mathrm{EtOH}$

$\mathrm{n}-\mathrm{C}_{4} \mathrm{OH}$

$\mathrm{i}-\mathrm{C}_{4} \mathrm{OH}$

$\mathrm{n}-\mathrm{C}_{6} \mathrm{OH}$

$\mathrm{i}-\mathrm{C}_{6} \mathrm{OH}$

$\mathrm{CH}_{4}$ (gas)

$\mathrm{CO}_{2}$ (gas)

isocaproate $\left(\mathrm{i}-\mathrm{C}_{6}\right)$ formation started to occur. When $\mathrm{n}-\mathrm{C}_{6}$ concentrations no longer increased at the end of the start-up (phase I) carrier material was added on day 45 . The reactor then reached a steady state from day 62 to day 78 in phase II. The $\mathrm{CO}_{2}$ headspace partial pressure was consistently below $1 \mathrm{kPa}$ as soon as chain elongation activity was observed, even after doubling the $\mathrm{CO}_{2}$ in phase III. The highest volumetric productivities and concentrations of $\mathrm{i}-\mathrm{C}_{6}$ were obtained during phase III at 
increased $\mathrm{CO}_{2}$ supply, reaching a rate of $57 \pm 4 \mathrm{mMC} /$ day, or $1.1 \pm 0.07 \mathrm{~g} / \mathrm{L} /$ day and a concentration of $125 \pm 6.6 \mathrm{mCM}$, or $2.43 \pm 0.13 \mathrm{~g} / \mathrm{L}$ (Table 5). However, selectivity towards $\mathrm{i}-\mathrm{C}_{6}$ (carbon per tot carbon in products) was highest in phase II (27\%) and dropped to $20 \%$ in phase III.

Excessive ethanol oxidation as shown in the table is calculated from the observed chain elongation activity and ethanol consumption using an earlier described method (de Leeuw et al., 2019). It is a stoichiometric analysis by which the amount of ethanol consumption is evaluated versus the observed chain elongation activity, using a fixed stoichiometry for reverse $\beta$-oxidation (Eq. 1 in introduction) with

Excessive ethanol oxidation (\%)

$$
=\left(1-\frac{\sum \text { Chain elongation activty }}{\text { observed ethanol consumption }}\right)
$$

(equation 3)

where $\sum$ chain elongation activity is the amount of ethanol that is necessary to perform all observed chain elongation (Roghair et al, 2018c). This value gives an indication of how much ethanol is not used for chain elongation but is instead oxidized to acetic acid and hydrogen. The results in Table 5 show that excessive ethanol oxidation had increased from $21 \pm 7 \%$ in phase II to $44 \pm 11 \%$ in phase IV.

The reactor was not allowed to develop a steady state in phase III because methane formation kept increasing, which was deemed unfavorable for chain elongation activity in the long term. Instead, the $\mathrm{CO}_{2}$ load was lowered from $0.36 \mathrm{NmL} / \mathrm{min}$ (phase III) to $0.18 \mathrm{NmL} / \mathrm{min}$ (phase IV) with two aims: 1) lower methanogenic activity and 2) investigate if the $\mathrm{i}-\mathrm{C}_{6}$ selectivity could be increased again. However, the reactor had also developed an increased alcohol (in particular i- $\mathrm{C}_{4} \mathrm{OH}$ ) productivity (see Table 5). Consequently, different conversion rates were observed in phase VI compared to phase II, although reactor operating conditions were the same. Alcohol $\left(n-\mathrm{C}_{4} \mathrm{OH}\right.$, i- $\mathrm{C}_{4} \mathrm{OH}, \mathrm{n}-\mathrm{C}_{6} \mathrm{OH}$ and $\mathrm{i}-\mathrm{C}_{6} \mathrm{OH}$ ) formation had increased from a combined selectivity of $10 \%$ in phase II to $16 \%$ in phase IV. Hexanol and isobutanol were the most predominant higher alcohols at concentrations of $19 \pm 3 \mathrm{mMC}\left(327 \pm 47 \mathrm{mgL}^{-1}\right)$ and $37 \pm 1 \mathrm{mMC}\left(684 \pm 24 \mathrm{mgL}^{-1}\right)$, respectively. Also, an increase in straight carboxylates was observed relative to phase II, while i-C 6 selectivity had dropped down to $12 \%$ in phase IV. Additionally, the hydrogen partial pressure had dropped below $1 \mathrm{kPa}$ from phase III onwards and did not recover to the levels observed in phase II (up to $10 \mathrm{kPa}$ ). The gas partial pressures in the reactor headspace are shown in Supplementary Figure S2 in the SI. Evidently, the average conversion rates in the reactor show a non-reversible behavior after the $\mathrm{CO}_{2}$ increase and decrease.

\section{Batches \\ Chain Elongation With Alternative Electron Acceptors During Acetate Limitation}

The dominant bioprocess throughout all batch series was straight chain elongation towards $\mathrm{n}-\mathrm{C}_{6}$. Depending on the added carboxylate $\left(\mathrm{i}-\mathrm{C}_{4}, \mathrm{n}-\mathrm{C}_{5}, \mathrm{i}-\mathrm{C}_{5}\right)$ besides acetate, varying amounts of alternative elongation products $\left(\mathrm{i}-\mathrm{C}_{6}, \mathrm{n}-\mathrm{C}_{7}\right.$ and $\mathrm{i}-\mathrm{C}_{7}$ ) were formed. The amount of acetate that was present in the beginning of the batch considerably affected the time it took for chain elongation to be observed. Concentration profiles of the second and third batch series are shown in Figures 2, 3, respectively. The carbon balances approach the value around $95 \%$ at the end of each batch, which is to be expected with these type of anaerobic fermentations (the remaining $5 \%$ is likely channeled into biomass formation).

It is relevant to emphasize that during all batches, except batch 2.B (where $65 \mathrm{mMC}$ acetate was added), a large fraction of ethanol (58-71\%) was not consumed and therefore still available as electron donor. Increasing the initial acetate concentration (2.B, Figure 2; Table 4) caused a substantial higher chain elongation activity towards $n-C_{6}$ (2.6 times more n- $\mathrm{C}_{6}$ was formed compared to 2 .A); more ethanol was consumed (only $5 \%$ remained) in this batch up to a higher hydrogen partial pressure $\left(\mathrm{p}_{\mathrm{H} 2}\right)$ and higher final acetate concentration. However,

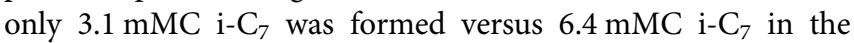
control with a low initial acetate amount (2.A). A low acetate concentration in combination with a high hydrogen partial pressure (Roghair et al., 2018a; Spirito et al., 2018) hampered chain elongation activity in the first two series. In control batch 1.G the absence of BES allowed methanogenesis to consume $\mathrm{CO}_{2}$ down to a partial pressure $<1 \mathrm{kPa}$, concomitant with more excessive ethanol oxidation to acetic acid that led to a $\mathrm{pH}$ drop to $<$ 5.7. These low $\mathrm{CO}_{2}$ partial pressure and $\mathrm{pH}$ values are limiting conditions for (ethanol-based) chain elongation bacteria (Barker and Taha, 1942; Tomlinson and Barker, 1954).

Alcohol formation was observed in all batches and showed a general trend that whenever a carboxylate is present, the corresponding alcohol is formed albeit up to a (10-50 times) lower concentration (i.e., $\mathrm{i}-\mathrm{C}_{4}$ led to $\mathrm{i}-\mathrm{C}_{4} \mathrm{OH}, \mathrm{n}-\mathrm{C}_{6}$ led to $\mathrm{n}-\mathrm{C}_{6} \mathrm{OH}$, etc.). The alcohol formation occurred in all batches up to a final concentration range between 1 and $5 \mathrm{mMC}$ for each produced alcohols species. The concentration profiles of metabolites in this lower concentration range are shown for all batches in Supplementary Figures S4, S6, S7, S9. Gas headspace partial pressure profiles of all batches are shown in Supplementary Figures S5, S6, S8, S10. In general, the batches with added BES show accumulation of hydrogen gas during chain elongation activity until activity halts.

\section{Chain Elongation of $\mathrm{i}-\mathrm{C}_{5}$ Towards $\mathrm{i}-\mathrm{C}_{7}$}

The first batch series showed $\mathrm{i}-\mathrm{C}_{7}$ formation in the batches fed with $\mathrm{i}-\mathrm{C}_{5}$, albeit in very low amounts (Supplementary Figures S3, S4). The L/D 2-methylbutanoate racemate (L/D 2-MB) was seemingly not utilized at all as substrate for chain elongation, as no hypothetical elongation product (4-methylhexanoate, 4-MHA) was observed. A general trend was observed that the lower concentration batches showed a faster onset of chain elongation activity, compared to the higher concentration batches. Small amounts of branched pentanol formation were observed in all batches regardless which form of branched pentanoate was available. Due to a relatively high standard error of the branched $\mathrm{C}_{5}$ analysis compared to the low $\mathrm{i}-\mathrm{C}_{7}$ and b-pentanol concentrations, it could not be determined whether i-C5 was molar-equally consumed. However, in all batches that did not contain $\mathrm{i}-\mathrm{C}_{5}$ no $\mathrm{i}-\mathrm{C}_{7}$ formation occurred. Additionally, the positive control batch without added yeast extract also showed $\mathrm{i}_{-} \mathrm{C}_{7}$ formation, excluding yeast extract conversion, as potential cause for $\mathrm{i}-\mathrm{C}_{7}$ formation. The likely chain elongation of $\mathrm{i}-\mathrm{C}_{5}$ towards $\mathrm{i}-\mathrm{C}_{7}$ 

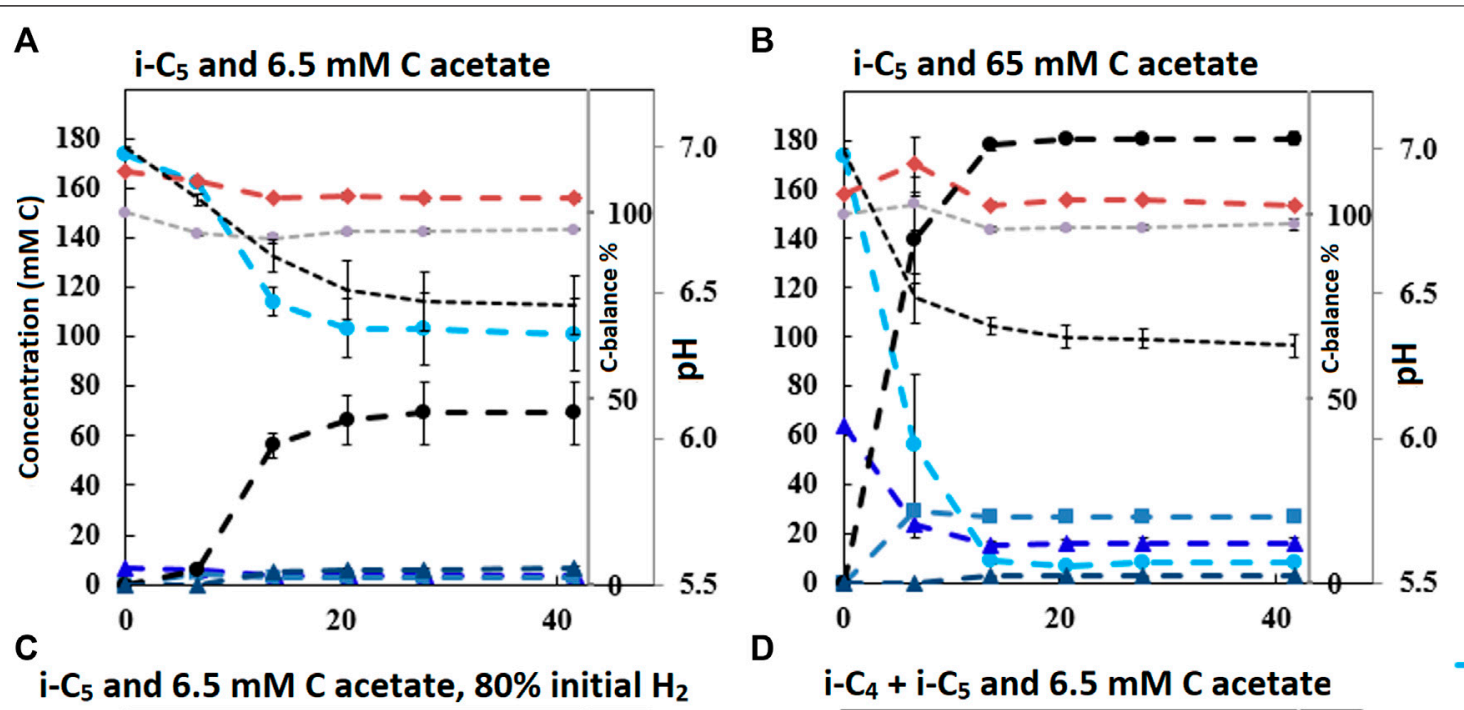

D
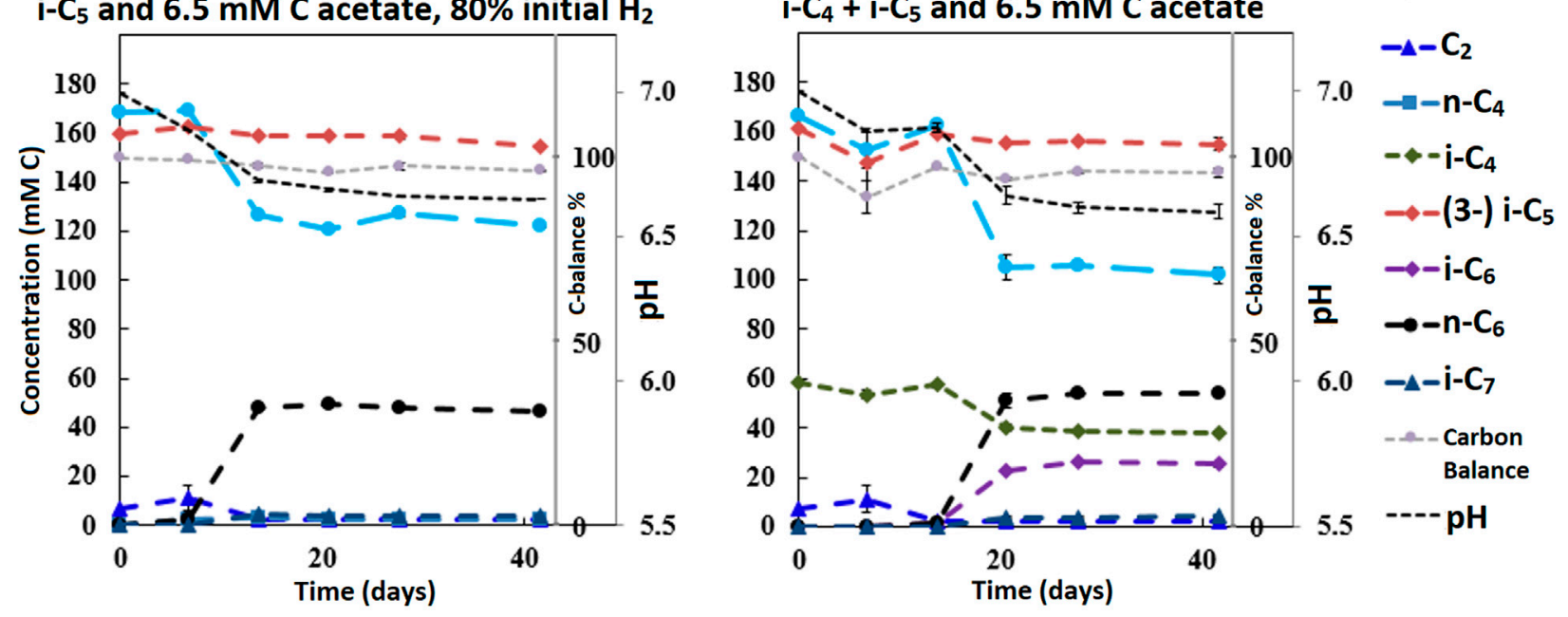

FIGURE 2 | Concentration profiles of batches performed with $\mathrm{i}_{-} \mathrm{C}_{5}$ as additional electron donor and varying levels of starting acetate amounts and hydrogen partial pressures (A-C). Batch (D) shows the preference for $\mathrm{i}-\mathrm{C}_{4}$ over $\mathrm{i}-\mathrm{C}_{5}$ as alternative electron acceptor leading to branched $\mathrm{MCFA}$ formation concomitant with straight chain elongation. The $\mathrm{i}_{-} \mathrm{C}_{5}$ addition results only in marginal $\mathrm{i}-\mathrm{C}_{7}$ formation. Concentration profiles of components that were present in lower concentration ranges are shown in Supplementary Figure S7.

accounted to $7.2 \%$ (based on carbon atoms) of the formed compounds in the best performing batch regarding i- $C_{7}$ formation (2.A). However, in this batch $98 \%$ of the supplied i- $C_{5}$ still remained unconverted. The $n-\mathrm{C}_{6}$ accounted to $79.6 \%$ (based on carbon atoms) of formed compounds. Hexanol and iso-pentanol constituted to 4.7 and $0.6 \%$, respectively, of the formed compounds. The final product selectivities (for $\mathrm{i}-\mathrm{C}_{7}, \mathrm{n}-\mathrm{C}_{6}$ and hexanol), and the percentages of unconverted ethanol for all other batches are shown in Tables 2-4.

\section{DISCUSSION}

\section{Acetate Availability and Branched Carboxylate Selectivity}

The continuous reactor experiment was operated without any acetate in the influent with the intention to maximize $\mathrm{i}-\mathrm{C}_{4}$ utilization during chain elongation and to maximize selectivity towards $\mathrm{i}-\mathrm{C}_{6}$ formation. Compared to a previous study on $\mathrm{i}_{-} \mathrm{C}_{6}$ formation (de Leeuw et al., 2019), the current system achieved a $30 \%$ higher volumetric i- $\mathrm{C}_{6}(57 \pm 4 \mathrm{mMC} /$ day, or $1.1 \pm 0.07 \mathrm{~g} / \mathrm{L} /$ day) formation rate and a $70 \%$ higher average $\mathrm{i}-\mathrm{C}_{6}$ broth concentration $(125 \pm 6.6 \mathrm{mMC}$, or $2.43 \pm$ $0.13 \mathrm{~g} / \mathrm{L}$ ) in phase III. During the whole operation period the reactor was operating under apparent $\mathrm{CO}_{2}$ limited conditions $(<1 \mathrm{kPa})$, meaning that the low availability limits chain elongation activity of well-known chain elongators such as $C$. kluyveri (Tomlinson and Barker, 1954). When the $\mathrm{CO}_{2}$ load in phase III was increased, overall chain elongation activity increased $\left(n-C_{6}\right.$ formation increase more than $\mathrm{i}-\mathrm{C}_{6}$ formation). There was a higher (branched) $\mathrm{i}-\mathrm{C}_{6}$ productivity, although selectivity towards $\mathrm{i}-\mathrm{C}_{6}$ had dropped (from $27 \%$ in phase II to $20 \%$ in phase III). Higher in situ acetate formation, both directly via the chain elongation metabolism and via 

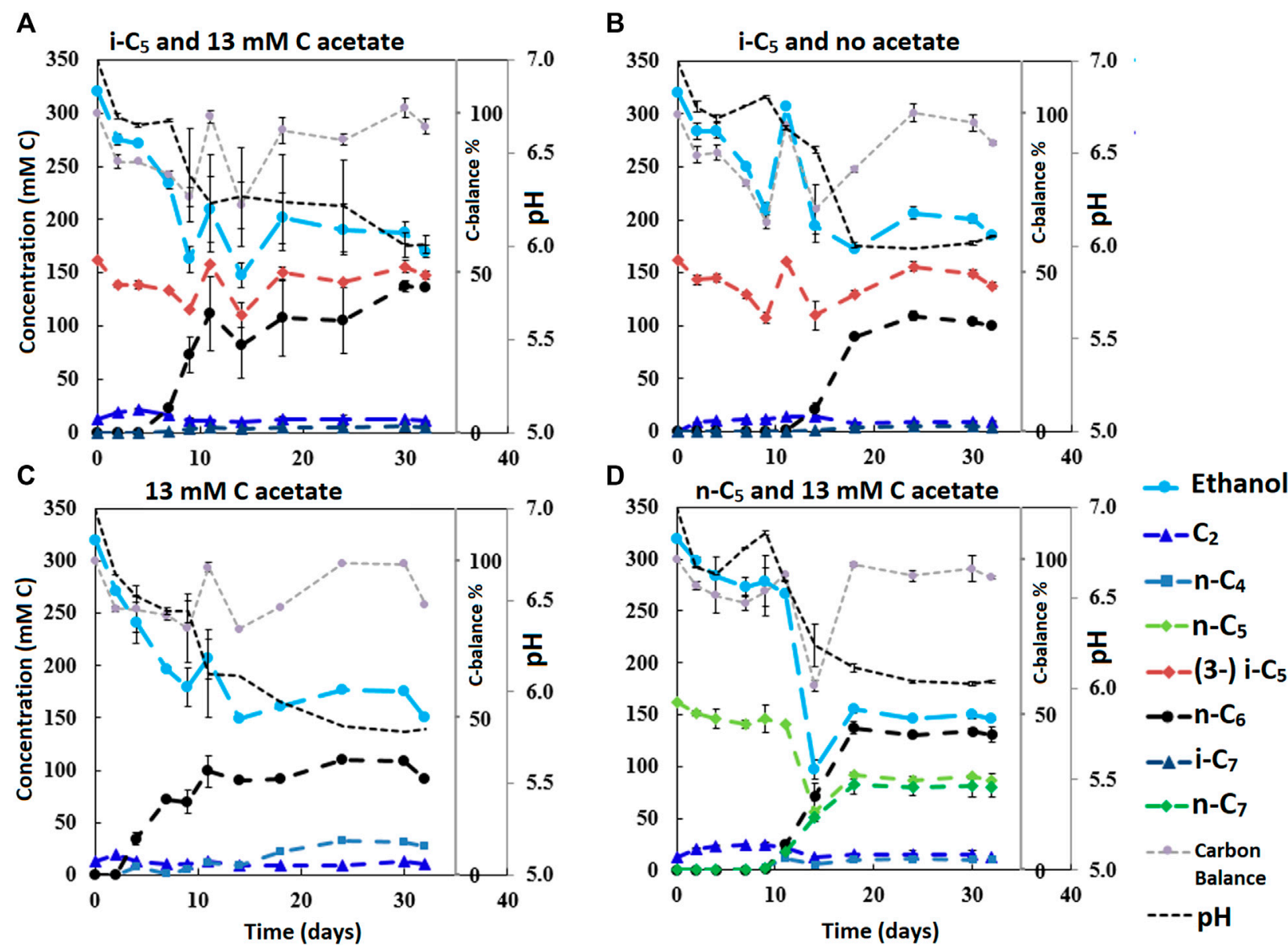

FIGURE 3 | The four batches illustrate the effect of different initial acetate amounts and added carboxylates beside acetate on chain elongation activity. Complete absence of initial acetate (B) causes a prolonged lag phase, whereas the addition of a small amount (A) sped up the onset of chain elongation by approximately 7 days. Additionally, the batch without any additional carboxylate besides acetate shows an even faster onset of chain elongation activity (C). The batch with added $n-C_{5}$ (D) shows $n-C_{6}$ and $n-C_{7}$ formation and no $\mathrm{i}-\mathrm{C}_{7}$ formation. Concentration profiles of components that were present in lower concentration ranges are shown in Supplementary Figure S9.

increased excessive ethanol oxidation led to increased straight chain elongation (see Supplementary Table S5). Homoacetogenesis cannot be fully excluded, however the low $\mathrm{CO}_{2}$ availability limits homoacetogenic activity that requires $\mathrm{CO}_{2}$ as electron acceptor.

The reactor behavior shows there is a tradeoff to be made when designing the system: 1 ) selectivity towards $\mathrm{i}-\mathrm{C}_{4}$ elongation is high during acetate and $\mathrm{CO}_{2}$ limitation (which reduces overall chain elongation activity), or 2) straight chain elongation is stimulated by lifting the $\mathrm{CO}_{2}$ limitation leading to a decreased selectivity towards alternative carboxylate elongation. In all phases $\mathrm{i}-\mathrm{C}_{4}$ was abundantly available, while acetate was only available via in situ formation. The sensitivity to increases in acetate show that there is a preference towards acetate as electron acceptor over $\mathrm{i}-\mathrm{C}_{4}$ (and $\mathrm{i}-\mathrm{C}_{5}$, in the batches) within the established chain elongation microbiome. In the third batch series it was observed that $\mathrm{CO}_{2}$ was consumed down to low partial pressures $(<1 \mathrm{kPa})$, while more $\mathrm{H}_{2}$ was consumed, and overall a higher percentage of ethanol was utilized for chain elongation compared to the previous batches; it suggests the microbiome had developed increased homoacetogenic activity.

\section{Low Affinity for i- $\mathrm{C}_{5}$ Elongation Suggests Co-Metabolism During Straight Chain Elongation}

The degree by which $\mathrm{i}-\mathrm{C}_{5}$ and $\mathrm{i}-\mathrm{C}_{4}$ are elongated in a batch system varied. Formation of $\mathrm{i}-\mathrm{C}_{7}$ contributed only $4.2 \%$ (based on carbon atoms) to the total produced compounds in the batch with both $\mathrm{i}-\mathrm{C}_{5}$ and $\mathrm{i}-\mathrm{C}_{4}(2 . \mathrm{D})$. In contrast, $\mathrm{i}-\mathrm{C}_{6}$ formation contributed for $27 \%$ to the total product spectrum, even though the molar concentration of $\mathrm{i}-\mathrm{C}_{5}$ was higher than $\mathrm{i}-\mathrm{C}_{4}$. With the $\mathrm{L} / \mathrm{D} 2$ methylbutanoate racemate batches no elongation product was observed at all and overall, the chain elongation rate diminished. Moreover, in the batch experiments a higher acetate availability negatively influences the selectivity towards branched chains, like 
what was observed in the continuous reactor. This is emphasized by the batches performed at $65 \mathrm{mMC}$ and $6.5 \mathrm{mMC}$ initial acetate. A higher initial acetate concentration (batch 2.B) increased total chain elongation activity, but considerably lowered the selectivity towards $\mathrm{i}-\mathrm{C}_{7}(1.4 \%)$ compared to the control (7.3\%) at low initial acetate amounts (batch 2.A). The results suggest the microbiome contains enzymes that can perform branched carboxylate elongation, but only to a certain degree. The varying selectivities can arise from two different scenarios: 1) acetate limitation and 2) no limitation (illustrated in Supplementary Figure S12). Hypothetically, the higher i- $C_{7}$ selectivity during acetate limitation (2.A) can arise from kinetic impairment of acetate elongation at low acetate concentrations, while branched carboxylate elongation occurs of maximum speed. In contrast, at higher acetate concentrations (2.B) the alleviated kinetic impairment leads to more acetate elongation relative to branched chain elongation, causing a lower $\mathrm{i}-\mathrm{C}_{7}$ selectivity.

The initially available acetate $(6.5 \mathrm{mMC}$ in 2 .A versus $65 \mathrm{mMC}$ in $2 . \mathrm{B}$ and $13 \mathrm{mMC}$ in $3 . \mathrm{A}$ versus $0 \mathrm{mMC}$ in $3 . \mathrm{B}$ ) in the batch series greatly affected the time it took for chain elongation to occur. These results are in line with earlier studies that show a reduced chain elongation activity during acetate limitation (Spirito et al., 2018). Interestingly, all batches, except for 2.A where $65 \mathrm{mMC}$ acetate was added, showed that first acetate formation started, before any chain elongation commenced (Supplementary Figures S4, S6, S7, S9). Despite presence of sufficient alternative electron acceptors, a minimum amount of acetate seems to be required for chain elongation to occur. The requirement of acetate hints towards a cometabolism for the branched electron acceptors within chain elongation, i.e., branched carboxylates are only elongated during straight chain elongation.

\section{Alcohol Formation as Electron Sink and Alternative Source for in situ Acetate Production}

The measured alcohol concentrations during the continuous reactor experiment followed a dependency on the concentrations of ethanol and acetate as well as on the concentration of the corresponding carboxylates (Figure 4A). This finding was in line with the earlier study where $\mathrm{i}-\mathrm{C}_{6}$ and alcohol $\left(\mathrm{i}-\mathrm{C}_{4} \mathrm{OH}, \mathrm{n}-\mathrm{C}_{6} \mathrm{OH}\right.$ and $\left.\mathrm{i}-\mathrm{C}_{6} \mathrm{OH}\right)$ formation were found (de Leeuw et al., 2019). It suggests that excessive (hydrogenogenic) ethanol oxidation is coupled to (hydrogenotrophic) carboxylate reduction within the microbiome as shown in Table 6, resulting in a net carboxylhydroxyl exchange reaction. A coupling of reactions would imply that the thermodynamics driving force is no longer affected by $\mathrm{pH}$ and hydrogen partial pressure $\left(\mathrm{p}_{\mathrm{H} 2}\right)$, in contrast to hydrogenotrophic carboxylate reduction to alcohols that is favored at a lowered $\mathrm{pH}$ and an elevated $\mathrm{p}_{\mathrm{H} 2}$ (See Supplementary Figure S2 for the $\mathrm{p}_{\mathrm{H} 2}$ in the continuous reactor) (Steinbusch et al., 2008). Figure 4B shows that after startup the $\Delta \mathrm{rG}^{1}$ (corrected for measured concentrations) of the combined reactions for each carboxylate-alcohol pair (when correcting for the broth concentrations of the reactants and products) remained between $15-25 \mathrm{~kJ}$ per reaction. This value is close to the currently known minimum required energy gain for a catabolic reaction to sustain microbial growth (Jackson and McInerney, 2002), and suggests that this bioconversion could be utilized as energy-providing route by organisms growing in a specific niche. It still needs to be revealed which organism(s) play(s) a role in this alcohol formation.

Possibly chain elongation microorganisms themselves are solely responsible for the formation of the longer alcohols. It is reported that Clostridium kluyveri, a well-known chain elongator, is able to produce small amounts of higher alcohols (Kenealy and Waselefsky, 1985). A batch series performed using pure Clostridium kluyveri with propionate and ethanol under different hydrogen pressures showed that propanol formation increased with an increasing $\mathrm{p}_{\mathrm{H} 2}$ (Candry et al., 2020). The alcohol formation during acetate limitation in combination with a high $\mathrm{p}_{\mathrm{H} 2}$ could hypothetically be method to get rid of excess electrons when chain elongation-coupled ethanol oxidation is thwarted due to high hydrogen partial pressures. Carboxylate reduction then replaces hydrogen formation as electron sink.

Alternatively, another specialized organism performing the hydroxyl-carboxyl exchange could be present. It would require an organism similar to Clostridium autoethanogenum (Diender et al., 2016) that can harvest the energy from ethanol-derived electrons via an energy-coupled transhydrogenase (Rnf complex) (Westphal et al., 2018) before reducing the carboxylates to alcohols. A second alternative would be syntrophic interaction between ethanol oxidizers and "hydrogenotrophic" carboxylate reducers [via $\mathrm{H}_{2}$ exchange and/or Direct Interspecies Electron Transfer (DIET) (Nozhevnikova et al., 2020)]. Although the thermodynamic calculations performed with macroscopic data show that the hydrogenotrophic carboxylate reduction is often unfeasible (Figure 4B), a syntrophic coupling of ethanol oxidation and carboxylate reduction would imply that the actual microscopic conditions are such that both (in syntophygrowing) microorganisms are able to proliferate (Smith and McCarty, 1989).

The gradual increase of $\mathrm{i}-\mathrm{C}_{4} \mathrm{OH}$ formation during phase III and the increased alcohol formation in phase IV compared to phase II indicate that this additional bioconversion capability had slowly become more prominent within microbiome. Consequently, the $\mathrm{p}_{\mathrm{H} 2}$ did not recover in phase IV to the earlier values in phase II $(9.2 \pm 1.3 \mathrm{kPa})$ after reducing the $\mathrm{CO}_{2}$ load; it was kept in a lower range $(0.6 \pm 0.4 \mathrm{kPa}$ in phase IV) by the microbiome, while alcohol formation spiked. The alcohol formation likely acted as an alternative electron sink when methane formation had dropped due to the sudden lower availability of $\mathrm{CO}_{2}$, as was also observed previously (de Leeuw et al., 2019).

The onset of the alcohol formation implies that the earlier achieved high selectivity towards $\mathrm{i}-\mathrm{C}_{6}$ in phase II could be transient. A low acetate concentration is used as steering parameter in this research to increase the selectivity towards i- $\mathrm{C}_{4}$ elongation. However, in combination with high ethanol and high other carboxylate amounts, a low acetate concentration leads 
TABLE 6 | Thermodynamic calculations for ethanol oxidation and carboxylate (n-butyrate as example) reduction towards the corresponding alcohol (n-butanol). $\Delta_{\mathrm{r}} \mathrm{G}^{1}$ indicates the reaction Gibbs free energy change at standard biological conditions $\left(298^{\circ} \mathrm{C}, \mathrm{pH} 7\right) . \Delta_{\mathrm{r}} \mathrm{G}^{2}$ and $\Delta_{\mathrm{r}} \mathrm{G}^{3}$ are corrected for reactants to products ratios (carboxylates and alcohols only) of 100 and 0.01 , respectively.

\begin{tabular}{|c|c|c|c|c|}
\hline Bioprocesses & Reaction & $\Delta_{\mathrm{r}} \mathbf{G}^{1}$ & $\Delta_{\mathrm{r}} \mathrm{G}^{2}$ & $\Delta_{\mathrm{r}} \mathrm{G}^{3}$ \\
\hline Hydrogenogenic ethanol oxidation & $\mathrm{CH}_{3} \mathrm{CH}_{2} \mathrm{OH}+\mathrm{H}_{2} \mathrm{O} \rightarrow \mathrm{CH}_{3} \mathrm{COO}^{-}+2 \mathrm{H}_{2}+\mathrm{H}^{+}$ & 8.35 & -3.07 & 19.76 \\
\hline Hydrogenotrophic carboxylate reduction (butyrate) & $\mathrm{C}_{3} \mathrm{H}_{7} \mathrm{COO}^{-}+2 \mathrm{H}_{2}+\mathrm{H}^{+} \rightarrow \mathrm{C}_{3} \mathrm{H}_{7} \mathrm{CH}_{2} \mathrm{OH}+\mathrm{H}_{2} \mathrm{O}$ & -16.15 & -27.56 & -4.73 \\
\hline Combined: Hydroxyl-carboxyl exchange & $\mathrm{C}_{3} \mathrm{H}_{7} \mathrm{COO}^{-}+\mathrm{CH}_{3} \mathrm{CH}_{2} \mathrm{OH} \rightarrow \mathrm{C}_{3} \mathrm{H}_{7} \mathrm{CH}_{2} \mathrm{OH}+\mathrm{CH}_{3} \mathrm{COO}^{-}$ & -7.80 & -30.63 & 15.03 \\
\hline
\end{tabular}

A

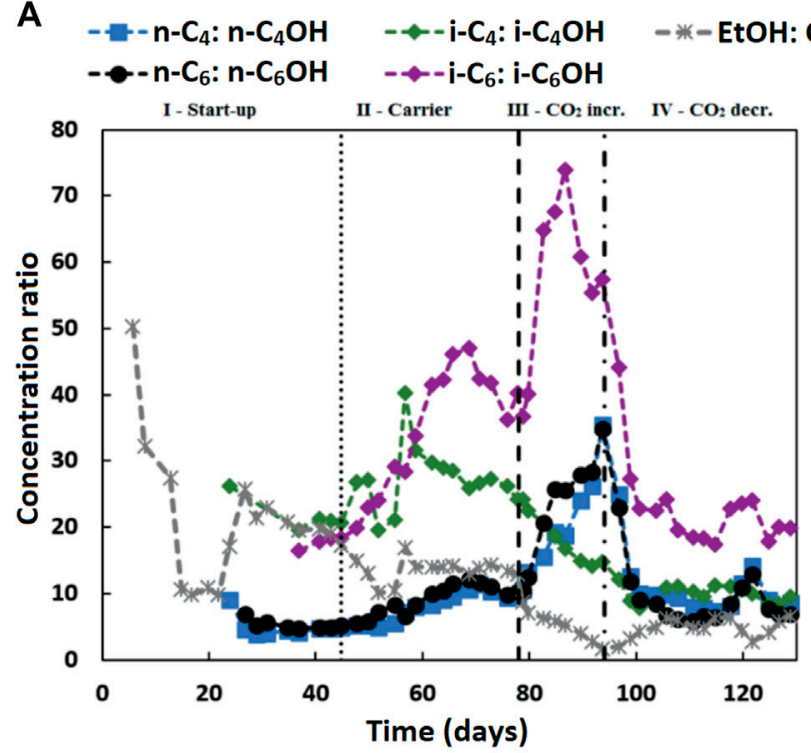

B

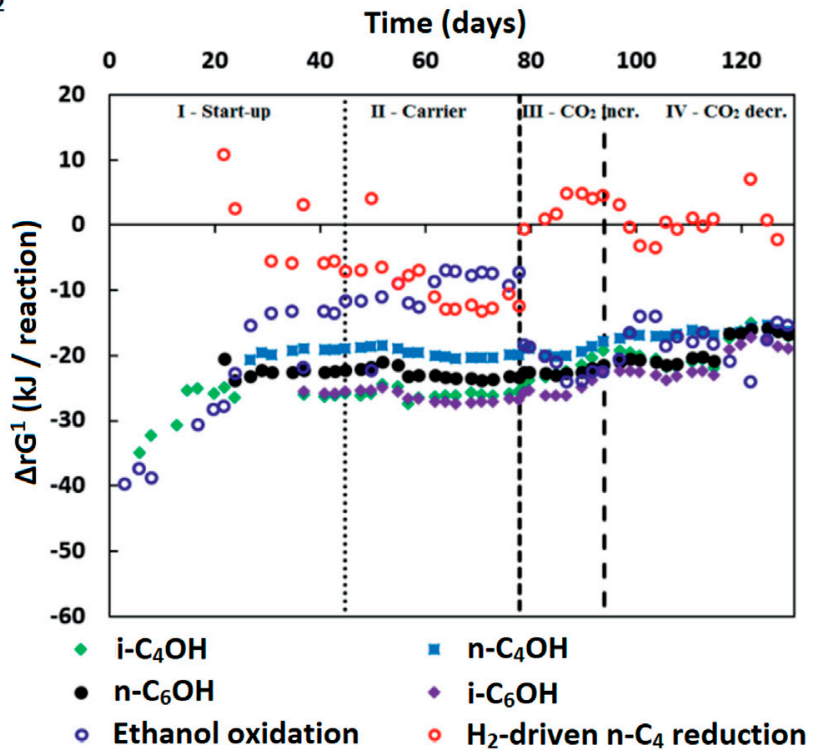

FIGURE 4 | (A) The concentration ratios of carboxylates to corresponding alcohols (and ethanol to acetate) are shown. These ratios seem to be inversely correlated to the ethanol to acetate ratio, especially in the later phases (III and IV), except for the $\mathrm{i}-\mathrm{C}_{4}$ to $\mathrm{i}-\mathrm{C}_{4} \mathrm{OH}$ ratio. Isobutyrate was continuously fed into the reactor and present at high concentrations in the broth. This would contribute to the driving force of isobutanol formation, while lessening the inverse correlation of the $\mathrm{i}-\mathrm{C}_{4}$ to $\mathrm{i}-\mathrm{C}_{4} \mathrm{OH}$ ratio to the ethanol to acetate ratio. (B) The Gibbs free energy change $\left(\Delta r \mathrm{G}^{1}\right)$ is shown for the reactions: Ethanol + Carboxylate $\rightarrow$ Acetate $+\mathrm{Corresponding} \mathrm{Alcohol}$ (for $\mathrm{iC}_{4} \mathrm{OH}$, $\mathrm{n}-\mathrm{C}_{4} \mathrm{OH}, \mathrm{n}-\mathrm{C}_{6} \mathrm{OH}$ and $\left.\mathrm{i}-\mathrm{C}_{6} \mathrm{OH}\right)$, direct ethanol oxidation and hydrogenotrophic butyrate reduction. The Gibbs free energy change was adjusted for the conditions (including $\mathrm{pH}$ and hydrogen partial pressure for ethanol oxidation and hydrogenotrophic reduction) in the reactor. The combined hydroxyl-carboxyl exchange reaction seems to remain stable in the range of $-15-25 \mathrm{~kJ}$ reaction per reaction. The used Gibbs formation energies and assumption for the calculations are given in Supplementary Table S6.

to a thermodynamic potential that allows an alternative source of in situ acetate formation via hydroxyl-carboxyl exchange.

\section{Outlook for Further Bioprocess Development}

Chain elongation microbiomes can be engineered to produce various chemicals depending on the supplied feedstock and steered reactor conditions. The higher branched and straight alcohol formations described in this research seem to be thermodynamically dependent on the reactant to product ratio. If the products could be removed in situ this could drive the reaction towards more straight and branched alcohol formation. Increasing the alcohol formation in this way could lead to an interesting biochemical production process in itself; the observed alcohol titers are in a suitable range for in situ extraction via gas stripping (Richter et al., 2016). This method may be used to develop processes that upgrade the ethanol in dilute ethanolcontaining residue streams to higher alcohols.

Branched carboxylates such as $\mathrm{i}-\mathrm{C}_{4}$ and apparently also $\mathrm{i}-\mathrm{C}_{5}$ can be used as electron acceptor during chain elongation fermentations with a varying extend of conversion. Operating the reactor under acetate and $\mathrm{CO}_{2}$ limited conditions increases the selectivity towards branched carboxylate elongation, but as a tradeoff overall chain elongation activity is reduced. The conversions of branched carboxylates to longer chains seem only to occur as a form of co-metabolism during straight chain elongation. It remains to be seen if the co-metabolism, that is expressed as a dependency on straight chain elongation activity, can be lifted. Acetate plays a pivotal role within the chain elongation metabolism as it can both serve as a primer and elongation (acetyl-CoA) unit (Schoberth and Gottschalk, 1969). 
However, research has already shown that it is possible to increase the affinity of butyrate relative to acetate for an engineered thiolase (Bonk et al., 2018), as well as first efforts to modify thiolases to use branched carboxylates as primers (Clomburg et al., 2018). Further efforts to tailor the thiolase and other involved enzymes via metabolic engineering could offer perspectives where the $\mathrm{k}_{\mathrm{cat}}$ and $\mathrm{K}_{\mathrm{m}}$ values for branched carboxylates and their conversion intermediates are increased. This metabolic engineering approach would require pure or coculture cultivation of the responsible bacteria, in contrast to the presented research. Aside from bioconversion kinetics, the metabolic fluxes could also have been hampered by uptake and export limitations.

Production of $\mathrm{i}-\mathrm{C}_{7}$ in the observed amounts in this study at this stage are unattractive for direct industrial applications compared to the formation of $\mathrm{n}-\mathrm{C}_{6}$. Still with fractional distillation of the produced broth considerable amounts of $\mathrm{i}-\mathrm{C}_{7}$ may be obtained. In the batch experiments $\mathrm{i}-\mathrm{C}_{5}$ is hardly elongated ( $\sim 98 \%$ remains unconverted) in the cases where it is supplied in excess and acetate is only present in low amounts. So far, it is remarkable that $\mathrm{i}-\mathrm{C}_{4}$ elongation has different kinetics compared to $\mathrm{i}-\mathrm{C}_{5}$ elongation. It shows that the involved microbiome has not developed fully optimized enzymes for the artificially imposed selective pressure with low amounts of acetate and large amounts of alternative electron acceptors. In addition to metabolic engineering approaches further research on selection pressure and natural adaptation in open culture microbiomes can provide a potential $\mathrm{i}-\mathrm{C}_{7}$ bioprocess development utilizing organic residual streams.

\section{DATA AVAILABILITY STATEMENT}

The raw data supporting the conclusion of this article will be made available by the authors in the DANS EASY research database with doi:10.17026/dans-x2v-xeta.

\section{REFERENCES}

Agler, M. T., Spirito, C. M., Usack, J. G., Werner, J. J., and Angenent, L. T. (2012). Chain Elongation with Reactor Microbiomes: Upgrading Dilute Ethanol to Medium-Chain Carboxylates. Energy Environ. Sci. 5 (8), 8189-8192. doi:10.1039/c2ee22101b

Agler, M. T., Wrenn, B. A., Zinder, S. H., and Angenent, L. T. (2011). Waste to Bioproduct Conversion with Undefined Mixed Cultures: the Carboxylate Platform. Trends Biotechnology 29 (2), 70-78. doi:10.1016/j.tibtech.2010.11.006

Ahmad, F. B., Zhang, Z., Doherty, W. O. S., and O'Hara, I. M. (2019). The Outlook of the Production of Advanced Fuels and Chemicals from Integrated Oil palm Biomass Biorefinery. Renew. Sustain. Energ. Rev. 109, 386-411. doi:10.1016/ j.rser.2019.04.009

Allison, M. J. (1978). Production of Branched-Chain Volatile Fatty Acids by Certain Anaerobic Bacteria. Appl. Environ. Microbiol. 35 (5), 872-877. doi:10.1128/aem.35.5.872-877.1978

Angenent, L. T., Richter, H., Buckel, W., Spirito, C. M., Steinbusch, K. J. J., Plugge, C. M., et al. (2016). Chain Elongation with Reactor Microbiomes: Open-Culture Biotechnology to Produce Biochemicals. Environ. Sci. Technol. 50 (6), 2796-2810. doi:10.1021/acs.est.5b04847

Atsumi, S., Hanai, T., and Liao, J. C. (2008). Non-fermentative Pathways for Synthesis of Branched-Chain Higher Alcohols as Biofuels. nature 451 (7174), 86-89. doi:10.1038/nature06450

\section{AUTHOR CONTRIBUTIONS}

KL planned and helped perform the experiments, analyzed the results, and wrote the manuscript. TA performed the experiments, analyzed the results and wrote an internal MSc thesis report. $\mathrm{CB}$ participated as a co-applicant of the ALWGR. 2015.8 project and planning of the study, contributed to experimental design and data interpretation, and revised the manuscript. DS is principal investigator and designer of the ALWGR. 2015.8 project, secured project funding, planned the study, contributed to experimental design and data interpretation, and revised the manuscript. All authors read and approved the final manuscript.

\section{FUNDING}

This research was carried out with help of ChainCraft B.V. and a grant from the Netherlands 408 Organisation for Scientific Research (NWO) with project number ALWGR. 2015.8.

\section{ACKNOWLEDGMENTS}

We thank ChainCraft B.V. for their help in carrying out the research. We thank the Netherlands Organisation for Scientific Research (NWO) with project number ALWGR. 2015.8 for providing financial support. Finally, we would like to thank the reviewers who helped to significantly improve the manuscript.

\section{SUPPLEMENTARY MATERIAL}

The Supplementary Material for this article can be found online at: https://www.frontiersin.org/articles/10.3389/fbioe.2021.697439/ full\#supplementary-material

Barker, H. A., and Taha, S. M. (1942). Clostridium Kluyverii, an Organism Concerned in the Formation of Caproic Acid from Ethyl Alcohol. J. Bacteriol. 43 (3), 347-363. doi:10.1128/jb.43.3.347-363.1942

Bonk, B. M., Tarasova, Y., Hicks, M. A., Tidor, B., and Prather, K. L. J. (2018). Rational Design of Thiolase Substrate Specificity for Metabolic Engineering Applications. Biotechnol. Bioeng. 115 (9), 2167-2182. doi:10.1002/ bit. 26737

Candry, P., Ulcar, B., Petrognani, C., Rabaey, K., and Ganigué, R. (2020). Ethanol: propionate Ratio Drives Product Selectivity in Odd-Chain Elongation with Clostridium Kluyveri and Mixed Communities. Bioresour. Technol. 313, 123651. doi:10.1016/j.biortech.2020.123651

Chen, W.-S., Strik, D. P. B. T. B., Buisman, C. J. N., and Kroeze, C. (2017). Production of Caproic Acid from Mixed Organic Waste: An Environmental Life Cycle Perspective. Environ. Sci. Technol. 51 (12), 7159-7168. doi:10.1021/ acs.est.6b06220

Chen, W. S., Ye, Y., Steinbusch, K. J. J., Strik, D. P. B. T. B., and Buisman, C. J. N. (2016). Methanol as an Alternative Electron Donor in Chain Elongation for Butyrate and Caproate Formation. Biomass and Bioenergy 93, 201-208. doi:10.1016/j.biombioe.2016.07.008

Chen, Y., Zhou, T., Liu, D., Li, A., Xu, S., Liu, Q., et al. (2013). Production of Butanol from Glucose and Xylose with Immobilized Cells of Clostridium Acetobutylicum. Biotechnol. Bioproc. E 18 (2), 234-241. doi:10.1007/s12257012-0573-5 
Chwialkowska, J., Duber, A., Zagrodnik, R., Walkiewicz, F., Łężyk, M., and OleskowiczPopiel, P. (2019). Caproic Acid Production from Acid Whey via Open Culture Fermentation - Evaluation of the Role of Electron Donors and Downstream Processing. Bioresour. Technol. 279, 74-83. doi:10.1016/j.biortech.2019.01.086

Clomburg, J. M., Contreras, S. C., Chou, A., Siegel, J. B., and Gonzalez, R. (2018). Combination of Type II Fatty Acid Biosynthesis Enzymes and Thiolases Supports a Functional $\beta$-oxidation Reversal. Metab. Eng. 45, 11-19. doi:10.1016/j.ymben.2017.11.003

De Groof, V., Coma, M., Arnot, T., Leak, D. J., and Lanham, A. B. (2019). Medium Chain Carboxylic Acids from Complex Organic Feedstocks by Mixed Culture Fermentation. Molecules 24 (3), 398. doi:10.3390/molecules24030398

de Leeuw, K. D., Buisman, C. J. N., and Strik, D. P. B. T. B. (2019). Branched Medium Chain Fatty Acids: Iso-Caproate Formation from Iso-Butyrate Broadens the Product Spectrum for Microbial Chain Elongation. Environ. Sci. Technol. 53 (13), 7704-7713. doi:10.1021/acs.est.8b07256

Diender, M., Stams, A. J. M., and Sousa, D. Z. (2016). Production of MediumChain Fatty Acids and Higher Alcohols by a Synthetic Co-culture Grown on Carbon Monoxide or Syngas. Biotechnol. Biofuels 9 (1), 82. doi:10.1186/s13068016-0495-0

Duboc, P., Schill, N., Menoud, L., Van Gulik, W., and Von Stockar, U. (1995). Measurements of Sulfur, Phosphorus and Other Ions in Microbial Biomass: Influence on Correct Determination of Elemental Composition and Degree of Reduction. J. Biotechnol. 43 (2), 145-158. doi:10.1016/0168-1656(95) 00135-0

Ganigué, R., Sánchez-Paredes, P., Bañeras, L., and Colprim, J. (2016). Low Fermentation $\mathrm{pH}$ Is a Trigger to Alcohol Production, but a Killer to Chain Elongation. Front. Microbiol. 7 (702). doi:10.3389/fmicb.2016.00702

Ghosh, P., Hickey, K. J., and Jaffe, S. B. (2006). Development of a Detailed Gasoline Composition-Based Octane Model. Ind. Eng. Chem. Res. 45 (1), 337-345. doi:10.1021/ie050811h

Grootscholten, T. I. M., Steinbusch, K. J. J., Hamelers, H. V. M., and Buisman, C. J. N. (2013). Chain Elongation of Acetate and Ethanol in an Upflow Anaerobic Filter for High Rate MCFA Production. Bioresour. Technol. 135, 440-445. doi:10.1016/j.biortech.2012.10.165

Grootscholten, T. I. M., Steinbusch, K. J. J., Hamelers, H. V. M., and Buisman, C. J. N. (2013). High Rate Heptanoate Production from Propionate and Ethanol Using Chain Elongation. Bioresour. Technol. 136, 715-718. doi:10.1016/ j.biortech.2013.02.085

Han, W., He, P., Shao, L., and Lü, F. (2019). Road to Full Bioconversion of Biowaste to Biochemicals Centering on Chain Elongation: A Mini Review. J. Environ. Sci., 86:50-64. doi:10.1016/j.jes.2019.05.018

Infantes, D., González del Campo, A., Villaseñor, J., and Fernández, F. J. (2012). Kinetic Model and Study of the Influence of $\mathrm{pH}$, Temperature and Undissociated Acids on Acidogenic Fermentation. Biochem. Eng. J. 66, 66-72. doi:10.1016/j.bej.2012.04.017

Jackson, B. E., and McInerney, M. J. (2002). Anaerobic Microbial Metabolism Can Proceed Close to Thermodynamic Limits. Nature 415 (6870), 454-456. doi: $10.1038 / 415454$ a

Jourdin, L., Raes, S. M., Buisman, C. J., and Strik, D. P. (2018). Critical Biofilm Growth throughout Unmodified Carbon Felts Allows Continuous Bioelectrochemical Chain Elongation from $\mathrm{CO} 2$ up to Caproate at High Current Density. Front. Energ. Res. 6, 7. doi:10.3389/fenrg.2018.00007

Jungermann, K., Thauer, R. K., and Decker, K. (1968). The Synthesis of OneCarbon Units from $\mathrm{CO} 2$ in Clostridium Kluyveri. Eur. J. Biochem. 3 (3), 351-359. doi:10.1111/j.1432-1033.1968.tb19536.x

Kenealy, W. R., and Waselefsky, D. M. (1985). Studies on the Substrate Range of Clostridium Kluyveri; the Use of Propanol and Succinate. Arch. Microbiol. 141 (3), 187-194. doi:10.1007/bf00408056

Kim, H., Jeon, B. S., and Sang, B-I. (2019). An Efficient New Process for the Selective Production of Odd-Chain Carboxylic Acids by Simple Carbon Elongation Using Megasphaera Hexanoica. Scientific Rep. 9 (1), 1-10. doi:10.1038/s41598-019-48591-6

Kleerebezem, R., Joosse, B., Rozendal, R., and Van Loosdrecht, M. C. M. (2015). Anaerobic Digestion without Biogas?. Rev. Environ. Sci. Biotechnol. 14 (4), 787-801. doi:10.1007/s11157-015-9374-6

Lee, I., Johnson, L. A., and Hammond, E. G. (1995). Use of Branched-Chain Esters to Reduce the Crystallization Temperature of Biodiesel. J. Am. Oil Chem. Soc. 72 (10), 1155-1160. doi:10.1007/bf02540982
Leng, L., Nobu, M. K., Narihiro, T., Yang, P., Amy Tan, G.-Y., and Lee, P.-H. (2019). Shaping Microbial Consortia in Coupling Glycerol Fermentation and Carboxylate Chain Elongation for Co-production of 1,3-propanediol and Caproate: Pathways and Mechanisms. Water Res. 148, 281-291. doi:10.1016/j.watres.2018.10.063

Levy, P. F., Sanderson, J. E., and Cheng, L. K. (1984). Kolbe Electrolysis of Mixtures of Aliphatic Organic Acids. J. Electrochem. Soc. 131 (4), 773-777. doi:10.1149/1.2115697

Li, F., Hinderberger, J., Seedorf, H., Zhang, J., Buckel, W., and Thauer, R. K. (2008). Coupled Ferredoxin and Crotonyl Coenzyme A (CoA) Reduction with NADH Catalyzed by the Butyryl-CoA Dehydrogenase/Etf Complex from Clostridium Kluyveri. J. Bacteriol. 190 (3), 843-850. doi:10.1128/ jb.01417-07

Liu, Q., Wang, C., Guo, G., Huo, W. J., Zhang, Y. L., Pei, C. X., et al. (2018). Effects of Branched-Chain Volatile Fatty Acids Supplementation on Growth Performance, Ruminal Fermentation, Nutrient Digestibility, Hepatic Lipid Content and Gene Expression of Dairy Calves. Anim. Feed Sci. Technol. 237, 27-34. doi:10.1016/j.anifeedsci.2018.01.006

Nozhevnikova, A. N., Russkova, Y. I., Litti, Y. V., Parshina, S. N., Zhuravleva, E. A., and Nikitina, A. A. (2020). Syntrophy and Interspecies Electron Transfer in Methanogenic Microbial Communities. Microbiology 89 (2), 129-147. doi:10.1134/s0026261720020101

Phillips, J. R., Klasson, K., Clausen E, C., and Gaddy J, L. (1993). Biological Production of Ethanol from Coal Synthesis Gas - Medium Development Studies1993. Appl. Biochem. Biotechnol. 39, 559-571. doi:10.1007/BF02919018

Richter, H., Molitor, B., Diender, M., Sousa, D. Z., and Angenent, L. T. (2016). A Narrow pH Range Supports Butanol, Hexanol, and Octanol Production from Syngas in a Continuous Co-culture of Clostridium Ljungdahlii and Clostridium Kluyveri with In-Line Product Extraction. Front. Microbiol. 7, 1773. doi:10.3389/fmicb.2016.01773

Roghair, M., Hoogstad, T., Strik, D. P. B. T. B., Plugge, C. M., Timmers, P. H. A., Weusthuis, R. A., et al. (2018). Controlling Ethanol Use in Chain Elongation by CO2Loading Rate. Environ. Sci. Technol. 52 (3), 1496-1505. doi:10.1021/ acs.est.7b04904

Roghair, M., Liu, Y., Adiatma, J. C., Weusthuis, R. A., Bruins, M. E., Buisman, C. J. N., et al. (2018). Effect of N-Caproate Concentration on Chain Elongation and Competing Processes. ACS Sustain. Chem. Eng. 6 (6), 7499-7506. doi:10.1021/acssuschemeng. 8 b00200

Roghair, M., Liu, Y., Strik, D. P. B. T. B., Weusthuis, R. A., Bruins, M. E., and Buisman, C. J. N. (2018). Development of an Effective Chain Elongation Process from Acidified Food Waste and Ethanol into N-Caproate. Front. Bioeng. Biotechnol. 6, 50. doi:10.3389/fbioe.2018.00050

Schoberth, S., and Gottschalk, G. (1969). Considerations on the Energy Metabolism of Clostridium Kluyveri. Archiv. Mikrobiol. 65 (4), 318-328. doi:10.1007/bf00412211

Seitz, H.-J., Schink, B., Pfennig, N., and Conrad, R. (1990). Energetics of Syntrophic Ethanol Oxidation in Defined Chemostat Cocultures. Arch. Microbiol. 155 (1), 82-88. doi:10.1007/bf00291279

Smith, D. P., and McCarty, P. L. (1989). Reduced Product Formation Following Perturbation of Ethanol- and Propionate-Fed Methanogenic CSTRs. Biotechnol. Bioeng. 34 (7), 885-895. doi:10.1002/bit.260340702

Spirito, C. M., Marzilli, A. M., and Angenent, L. T. (2018). Higher Substrate Ratios of Ethanol to Acetate Steered Chain Elongation Towardn-Caprylate in a Bioreactor with Product Extraction. Environ. Sci. Technol. 52 (22), 13438-13447. doi:10.1021/acs.est.8b03856

Spirito, C. M., Richter, H., Rabaey, K., Stams, A. J., and Angenent, L. T. (2014). Chain Elongation in Anaerobic Reactor Microbiomes to Recover Resources from Waste. Curr. Opin. Biotechnol. 27, 115-122. doi:10.1016/j.copbio.2014.01.003

Steinbusch, K. J., Hamelers, H. V., and Buisman, C. J. (2008). Alcohol Production through Volatile Fatty Acids Reduction with Hydrogen as Electron Donor by Mixed Cultures. Water Res. 42 (15), 4059-4066. doi:10.1016/ j.watres.2008.05.032

Steinbusch, K. J. J., Hamelers, H. V. M., Plugge, C. M., and Buisman, C. J. N. (2011). Biological Formation of Caproate and Caprylate from Acetate: Fuel and Chemical Production from Low Grade Biomass. Energ. Environ. Sci. 4 (1), 216-224. doi:10.1039/c0ee00282h

Tan, Y. D., and Lim, J. S. (2019). Feasibility of palm Oil Mill Effluent Elimination towards Sustainable Malaysian palm Oil Industry. Renew. Sustain. Energ. Rev. 111, 507-522. doi:10.1016/j.rser.2019.05.043 
Tomlinson, N., and Barker, H. A. (1954). Carbon Dioxide and Acetate Utilization by Clostridium Kluyveri. J. Biol. Chem. 209 (2), 585-595. doi:10.1016/s00219258(18)65485-7

Tomlinson, N. (1954). Carbon Dioxide and Acetate Utilization by Clostridium Kluyveri. J. Biol. Chem. 209 (2), 597-603. doi:10.1016/s0021-9258(18) 65486-9

Vogels, G. D., Keltjens, J. T., Hutten, T. J., and Van Der Drift, C. (1982). Coenzymes of Methanogenic Bacteria. Zentralblatt für Bakteriologie Mikrobiologie Hygiene: Abt. Originale C: Allgemeine, Angewandte Ökologische Mikrobiologie 3 (2), 258-264. doi:10.1016/s0721-9571(82)80038-0

Westphal, L., Wiechmann, A., Baker, J., Minton, N. P., and Müller, V. (2018). The Rnf Complex Is an Energy-Coupled Transhydrogenase Essential to Reversibly Link Cellular NADH and Ferredoxin Pools in the Acetogen Acetobacterium Woodii. J. Bacteriol. 200 (21), e00357-18. doi:10.1128/ jb.00357-18

Xin, F., Wu, Y.-R., and He, J. (2014). Simultaneous Fermentation of Glucose and Xylose to Butanol by Clostridium Sp. Strain BOH3. Appl. Environ. Microbiol. 80 (15), 4771-4778. doi:10.1128/aem.00337-14

Yang, X., Liu, X., Chen, S., Liu, G., Wu, S., and Wan, C. (2016). Volatile Fatty Acids Production from Codigestion of Food Waste and Sewage Sludge Based on $\beta$-Cyclodextrins and Alkaline Treatments. Archaea 2016, 1698163. doi:10.1155/ 2016/1698163

Zhang, Z. C., Dery, M., Zhang, S., and Steichen, D. (2004). New Process for the Production of Branched-Chain Fatty Acids. J. Surfact Deterg 7 (3), 211-215. doi:10.1007/s11743-004-0306-x
Zhu, X., Tao, Y., Liang, C., Li, X., Wei, N., Zhang, W., et al. (2015). The Synthesis of N-Caproate from Lactate: a New Efficient Process for MediumChain Carboxylates Production. Scientific Rep. 5, 14360. doi:10.1038/ srep 14360

Zhu, X., Zhou, Y., Wang, Y., Wu, T., Li, X., Li, D., et al. (2017). Production of HighConcentration N-Caproic Acid from Lactate through Fermentation Using a Newly Isolated Ruminococcaceae Bacterium CPB6. Biotechnol. Biofuels 10 (1), 102. doi:10.1186/s13068-017-0788-y

Conflict of Interest: The authors declare that the research was conducted in the absence of any commercial or financial relationships that could be construed as a potential conflict of interest.

Publisher's Note: All claims expressed in this article are solely those of the authors and do not necessarily represent those of their affiliated organizations, or those of the publisher, the editors and the reviewers. Any product that may be evaluated in this article, or claim that may be made by its manufacturer, is not guaranteed or endorsed by the publisher.

Copyright (C) 2021 de Leeuw, Ahrens, Buisman and Strik. This is an open-access article distributed under the terms of the Creative Commons Attribution License (CC BY). The use, distribution or reproduction in other forums is permitted, provided the original author(s) and the copyright owner(s) are credited and that the original publication in this journal is cited, in accordance with accepted academic practice. No use, distribution or reproduction is permitted which does not comply with these terms. 